\title{
Polyethersulfone Hollow Fiber Membranes Developed for Oily Emulsion Treatment
}

\author{
Rodholfo da Silva Barbosa Ferreira ${ }^{a}{ }^{\mathbb{D}}$, Sandriely Sonaly Lima Oliveira ${ }^{\circledR}$, Aline Florindo Salviano $^{\circledR}$, \\ Edcleide Maria Araújo $^{a^{\circledR}}$, Amanda Melissa Damião Leite ${ }^{\circledR}$, Hélio de Lucena Lira $^{\circledR}$ \\ ${ }^{a}$ Laboratório de Desenvolvimento de Membranas, Universidade Federal de Campina Grande, Campina \\ Grande, PB, Brasil \\ ${ }^{b}$ Escola de Ciências \& Tecnologia (EC\&T), Universidade Federal do Rio Grande do Norte, Natal, RN, Brasil
}

Received: December 08, 2018; Revised: June 12, 2019; Accepted: June 18, 2019

\begin{abstract}
Polyethersulfone (PES) hollow fiber membranes were produced, containing 3\% of two types of clay (Brasgel PA - MMT and Cloisite NA - CLNa), in order to modify the characteristics of the polyethersulfone membrane. By means of the X-ray diffraction, it was possible to observe an exfoliated and/or partially exfoliated structure in the membranes containing clay. From the analysis of contact angle, it was possible to notice an increase in the hydrophilicity of the membrane with the introduction of the clay. Through scanning electron microscopy (SEM), the morphology of the porous support of the membrane was modified with addition of clay, favoring greater uniformity of the pores and fingers. In the flow measurements with distilled water, the membranes with clay obtained the highest flows, being the greater flow with the Cloisite Na clay $\left(\sim 22 \mathrm{~L} / \mathrm{h} \cdot \mathrm{m}^{2}\right)$ and was in agreement with the contact angle results. In the analysis of permeation with the oily emulsion, the membrane with Brasgel PA clay in its structure presented the greatest flow $\left(\sim 16 \mathrm{~L} / \mathrm{h} . \mathrm{m}^{2}\right)$ and the membrane with Cloisite $\mathrm{Na}$ presented the greatest yield (78.28\%). Therefore, the clay acted by modifying both the morphology and the hydrophilicity of the polyethersulfone membrane, improving flow and yield.
\end{abstract}

Keywords: Hollow fiber membrane, polyethersulfone, clay, oily emulsion.

\section{Introduction}

Nowadays, the membrane separation process (MSP) has been widely used in the treatment of effluents worldwide. MSP covers the most diverse processes in the treatment of water, such as: purification, brackish water desalination, wastewater recovery and treatment of hazardous industrial wastes to the environment ${ }^{1-3}$. In this context, the advancement of this technology, including selective permeation and reduced energy consumption ${ }^{4}$, has brought about a great development in the area of effluent treatment, improving the quality of public health and the environment, replacing traditional methods of separation ${ }^{5,6}$.

Due to their excellent properties, some polymer membranes have been applied in the treatment of water contaminated by oily materials ${ }^{7,8}$. It is of fundamental importance for society to treat this effluent since oily water generated in several sectors is disposed of in the environment without any adequate treatment, thus bringing risks to the environment and to human health ${ }^{7}$.

Polymer membranes are changing every day, from the initial development of a film to its fiber form, and even the advancement of the composite membrane, in order to obtain better separation performances. In order to obtain membranes with a particularly efficient geometry for various applications and together with a suitable morphology, hollow fiber membranes have been manufactured. Such membranes are generally fabricated using the process known as spinning, being a variation of the phase inversion process in which the polymer is dissolved and then extruded (extruder with two concentric circular holes) towards a bath containing non-solvent, where precipitation will occur'.

The preparation of the hollow fiber polymeric membranes is made from different materials, but polyethersulfone (PES) is one of the polymers that has attracted attention because of its excellent chemical resistance, mechanical strength, high stiffness, thermal stability and biological compatibility ${ }^{10}$. Even with all these properties suitable for producing good membranes, there are still problems with hydrophilicity. Therefore, some researchers try to solve this problem by adding inorganic materials to the polymer matrix ${ }^{11,12}$. Muhaman, Salim \& $\mathrm{Lau}^{13}$, added $\mathrm{SiO}_{2}$ nanoparticles on polyethersulfone membranes to improve hydrophilicity and consequently filtration in water treatment. Zangeneh et al. ${ }^{10}$ studied the influence of the $\mathrm{TiO}_{2}-\mathrm{SiO}_{2}$ addition doped- with boron on polyethersulfone membranesThe addition of nanoparticles modified the morphology, increased porosity and membrane flux.

The aim of this work is to produce polyethersulfone hollow fiber membranes with montmorillonite clay nanoparticles for the treatment of oily emulsions. 


\section{Materials and Methods}

\subsection{Materials}

The polymer used as matrix for the production of the membranes was polyethersulfone, under the tradename Veradel $^{\circledR} 3000 \mathrm{P}(\mathrm{Mw}=63,000 \mathrm{~g} / \mathrm{mol})$, purchased by Solvay. Brasgel PA (MMT) and Cloisite Na (CLNa) clays were used as nanoparticles, both supplied by Bentonit União Nordeste (BUN), in the form of powder, particle size less than $74 \mu \mathrm{m}$ and cation exchange capacity of $90 \mathrm{meq} / 100 \mathrm{~g}$.

N, N-Dimethylformamide P.A./ACS was used as solvent, to obtain polymer solution and it was also used in the internal liquid for membranes. The polyvinylpyrrolidone (PVP) was used to control the viscosity of the polymer solution. Both were purchased from Labsynth Produtos para Laboratório Ltda.

\subsection{Methods}

Initially, polyethersulfone was dried at $80^{\circ} \mathrm{C}$ for 24 hours to eliminate adsorbed water. For the pure polymer membrane, the solvent was mixed with the polymer and PVP under stirring for 1 hour at a speed of $1200 \mathrm{rpm}$. For the clay-containing membranes, the dispersion was initially prepared with clay and solvent, under stirring for 1 hour at $1200 \mathrm{rpm}$. After that time, the polymer and the viscosifier were added into the solution under the same period and stirring velocity. After the preparation the solutions were left resting for a period of 24 hours, so that the bubbles were eliminated and the solution stabilized. The compositions of the solutions are presented in Table 1.

The hollow fiber membranes were prepared using a laboratory extruder, comprising two concentric orifices, allowing the simultaneous extrusion of the inner liquid and the polymeric solution. After extrusion, the polymeric solution remained in contact with the non-solvent bath until complete precipitation. Soon after, the fibers were collected, washed with distilled water and remained in it for 24 hours. In order to change the morphology of the membranes, $10 \%$ of DMF solvent was added in the inner liquid, to delay the precipitation of the membranes. Fig. 1 shows the schematic representation of the process to obtaining the hollow fiber membranes.

The parameters established for the production of the membranes are in Table 2.

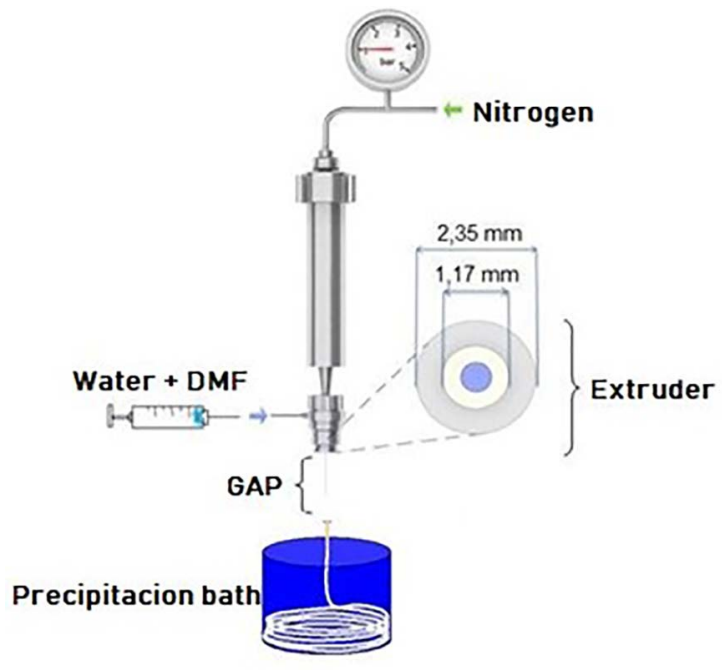

Figure 1. Schematic representation of the process to obtain hollow fiber membranes by spinning solution.

Table 2. Spinning conditions of hollow fiber membranes.

\begin{tabular}{lc}
\hline PARAMETERS & VALUES \\
\hline Solution viscosity & $4200-4400 \mathrm{mPa} . \mathrm{s}$ \\
Solution temperature & $\approx 26^{\circ} \mathrm{C}$ \\
GAP & $5 \mathrm{~cm}$ \\
Internal fluid flow & $3 \mathrm{~g} / \mathrm{min}$ \\
Solution flow & $6 \mathrm{~g} / \mathrm{min}$ \\
\hline
\end{tabular}

\subsection{Characterizations}

Chemical analysis of the clays were performed by semiquantitative method in a Shimadzu EDX 720 equipment, under a nitrogen atmosphere. X-ray diffraction analysis for the clays were conducted on a Shimadzu XRD-6000 equipment using copper $\mathrm{K} \alpha$ radiation, $40 \mathrm{kV}$ voltage, 30 $\mathrm{mA}$ current, scanning range from 2 to $60^{\circ}$ and $2^{\circ} / \mathrm{min}$ scanning speed. For the membranes, the BRUKER D2 PHASER diffractometer was used, with scanning range, from 3 to $70^{\circ}$. The contact angle analysis was performed by the sessile drop method through a portable contact angle equipment Phoenix-i model of the Electro Optics - SEO Surface. The drop was manually formed by means of a micrometric doser. The image of the drop is captured by the camera built into the equipment and analyzed in the software.

Table 1. Compositions of the spinning solutions.

\begin{tabular}{|c|c|c|c|c|}
\hline \multirow{2}{*}{ SAMPLE } & \multirow{2}{*}{$\begin{array}{l}\text { SOLVENT } \\
(\mathrm{wt} \%)\end{array}$} & \multicolumn{2}{|c|}{ SOLID COMPONENTS = POLYMER + CLAY $(23 \%)$} & \multirow{2}{*}{$\begin{array}{l}\text { PVP ADDITIVE } \\
(\mathrm{wt} \%)\end{array}$} \\
\hline & & POLYMER (wt\%) & CLAY $(w t \%)$ & \\
\hline Pure PES & 70 & 100 & - & 7 \\
\hline MMT 3\% & 70 & 97 & 3 & 7 \\
\hline CL Na 3\% & 70 & 97 & 3 & 7 \\
\hline
\end{tabular}


Thirty pictures were taken within 10 seconds of interval. For the analysis of the hollow fiber membrane morphology, cross-sectional photomicrographs of external (ECS) and internal (ICS) surface were made, using a VEGA 3 - TESCAN equipment, operating at $30 \mathrm{kV}$. For the flow measurements with distilled water and with the water/oil emulsion, modules with five hollow fiber membranes and $20 \mathrm{~cm}$ of length were produced. The total membrane area was approximately 89 $\mathrm{cm}^{2}$. Fig. 2 illustrates the module produced for the flow measurements. Calculation of the flux $(\mathrm{J})$ of the volumetric permeate for all membranes was determined by equation 1 :

$$
J=\frac{\text { Permeate volume }}{\text { Time. Membrane area }}
$$

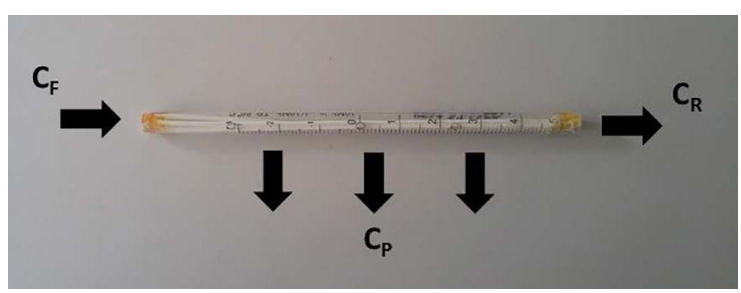

Figure 2. Membrane module with five hollow fiber membranes inside. $\mathrm{C}_{\mathrm{F}}, \mathrm{C}_{\mathrm{P}}$ and $\mathrm{C}_{\mathrm{R}}$ indicate feed, permeate and rejection concentrations, respectively.

For the flow measurement with water/oil, an oil emulsion was initially produced, with $200 \mathrm{mg} . \mathrm{L}^{-1}$ oil, produced under stirring in Ultra Turrax, under a speed of 15,000 rpm, for a period of 30 minutes. An aliquot of this emulsion was collected and the oil value in mg. $\mathrm{L}^{-1}$ was measured on UV-Visible. To measure the oil concentrations in the feed and permeated, it was used the spectrophotometer (UV) UV-VIS Biochrom Libra S50. The sample preparation followed the instructions of the Petrobras Manual described by Cirne et al. ${ }^{14}$.

\section{Results and Discussion}

Table 3 show the semi-quantitative chemical analysis for Brasgel PA(MMT) and Cloisite $\mathrm{Na}$ (CLNa) clays It is possible to observe that the two clays contain the characteristic elements of bentonite clay, such as alumina $\left(\mathrm{Al}_{2} \mathrm{O}_{3}\right)$ and silica $\left(\mathrm{SiO}_{2}\right)$. For Brasgel PA clay it is possible to observe the presence of exchangeable cations in the form of oxides, such as $\mathrm{MgO}$, $\mathrm{Na}_{2} \mathrm{O}$ and $\mathrm{CaO}$, due to the polycationic characteristics of this clay. Cloisite $\mathrm{Na}$ has a $\mathrm{Na}_{2} \mathrm{O}$ value much higher than that of $\mathrm{CaO}$, thus assigning a natural sodium characteristic ${ }^{15}$.

The chemical analysis also allows to verify the presence of accessory minerals in the two types of clays and represented by iron $\left(\mathrm{Fe}_{2} \mathrm{O}_{3}\right)$, calcium $(\mathrm{CaO})$, titanium $\left(\mathrm{TiO}_{2}\right)$, potassium $\left(\mathrm{K}_{2} \mathrm{O}\right)$ oxides $^{16}$.

Fig. 3 illustrates the X-ray patterns of Brasgel PA clays and Cloisite Na. The MMT clay presented a basal interplanar distance $\left(\mathrm{d}_{001}\right)$ of $14.50 \AA$ and Cloisite Na 14.82 $\AA$, characterizing the two clays as montmorillonites ${ }^{17}$.
Table 3. Chemical analysis by X-ray fluorescence of Brasgel PA and Cloisite Na clays.

\begin{tabular}{lcc}
\hline \multirow{2}{*}{ Present elements } & \multicolumn{2}{c}{ Clays (contents in \%) } \\
\cline { 2 - 3 } & MMT & CLNa \\
\hline $\mathrm{SiO}_{2}$ & 63.8 & 55.1 \\
$\mathrm{Al}_{2} \mathrm{O}_{3}$ & 20.2 & 27.1 \\
$\mathrm{Fe}_{2} \mathrm{O}_{3}$ & 9.0 & 2.6 \\
$\mathrm{MgO}$ & 2.4 & 4.2 \\
$\mathrm{Na}_{2} \mathrm{O}$ & 1.6 & 10.1 \\
$\mathrm{CaO}$ & 1.5 & 0.3 \\
$\mathrm{TiO}_{2}$ & 0.9 & 0.1 \\
$\mathrm{~K}_{2} \mathrm{O}$ & 0.32 & - \\
Others & 0.56 & 0.47 \\
\hline
\end{tabular}

This interplanar distance is characteristic of montmorillonites containing $\mathrm{Na}^{+}$ions in their structures. Characteristic peaks of impurities such as kaolinite (K) at $19^{\circ}$ were found for both types of clays. It is also possible to observe the presence of characteristic peaks of some constituent materials, such as quartz (Q), in the range of 22-30 $0^{\circ 6,17}$.

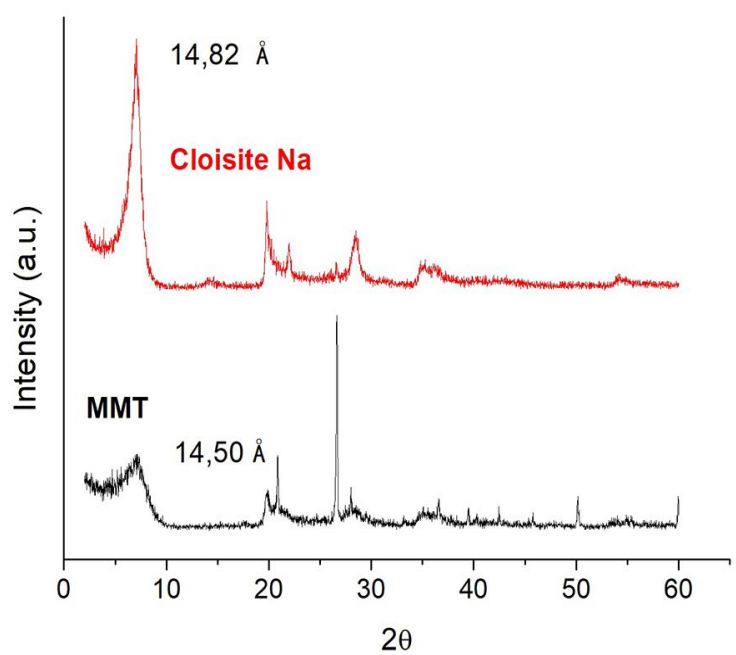

Figure 3. X-ray diffraction patterns of the Brasgel PA and Cloisite Na clays.

The Cloisite Na clay, presented lesser amount of accessory materials than Brasgel PA clay. This can be observed for angles larger than $10^{\circ}$, where Cloisite $\mathrm{Na}$ presents a higher degree of purity.

In Fig. 4, the X-ray diffraction patterns of the membranes obtained with the pure polymer and for the membranes with the two types of clay (MMT and CLNa) are shown.

The membrane obtained from the pure polymer illustrates that preparation process influenced the structure of the PES, i.e., the solvent (DMF) affected the crystallinity of the polymer, with the appearance of a peak before $20^{\circ 12,18}$. 


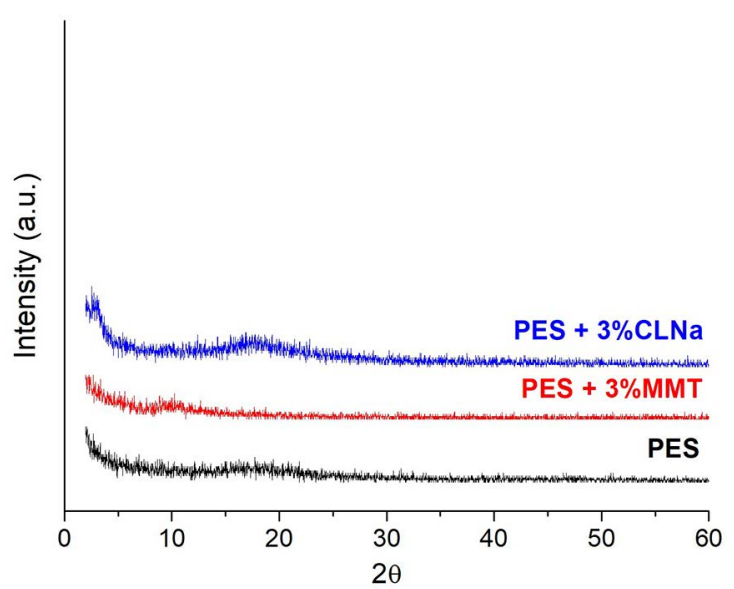

Figure 4. XRD diffractions patterns of PES and PES membranes with 3\% MMT and CLNa.

It is possible to observe that the characteristic peak of montmorillonite clay is not evident in membranes containing $3 \%$ MMT and CLNa. This may indicate a possible exfoliated and/or partially exfoliated structure. According to Liang et al. ${ }^{12}$, the non-appearance of the characteristic montmorillonite peak can be attributed to an efficient intercalation of the polymer chains between the lamellae of the clay, generating an exfoliated and/or partially exfoliated structure.

According to Ghaemi et al. ${ }^{19}$ and Wang, Zhang \& $\mathrm{Ye}^{20}$, membranes with exfoliated structures have also been observed, which can be attributed to the entropy increase when the clay layers are dispersed in DMF. Then, the dispersion of DMF/ clay is added to the PES/DMF solution, thereby, disturbing the arrangement of the layers of the clay. The delaminated clay layers favor the intercalation of the polymeric chains with the stirred solution. When the film is immersed in the nonsolvent bath, the solvent is continuously exchanged for water (non-solvent), reducing the diffusion rate. Clay layers filled with polymer chains form intercalated/exfoliated structures where diffusion can be hampered by the precipitated surface.

Fig. 5 shows the contact angle analysis for the membranes produced. The contact angle measurement is a way to evaluate the hydrophilicity and hydrophobicity properties of the membrane surface, where this implies the interaction energy between the surface and the liquid used ${ }^{21-23}$. Thus, it is an extremely important analysis regarding the influence on the flow properties and the antifouling capacity of the membranes.

For the membrane produced from the pure PES, it was possible to observe a low hydrophilicity of the membrane. The membrane had an average contact angle of $52^{\circ}$, where it was the lowest value for all membranes. Thus, showing that the pure PES membrane is the least hydrophilic ${ }^{22}$.

For the membranes containing clay, what happened was expected, since there was a greater decrease of the average contact angle in relation to the PES membrane, thus evidencing that the presence of clay acts directly on the hydrophilicity of the membrane.

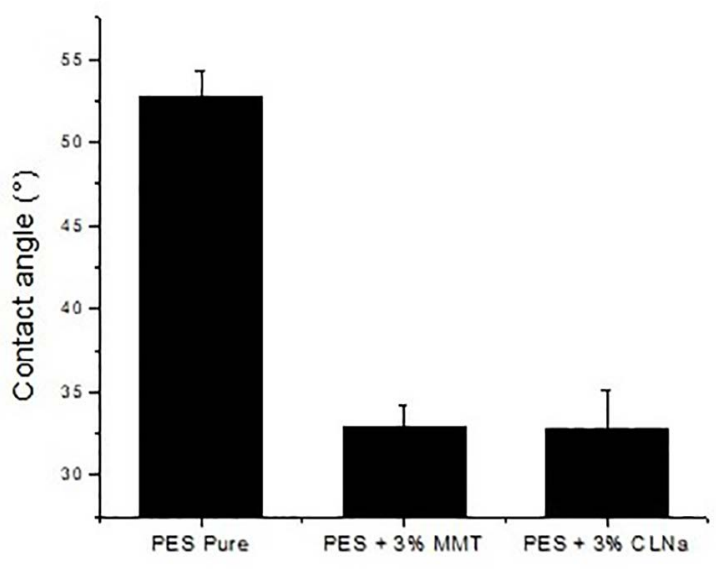

Figure 5. Contact angle for PES and PES flat membranes with 3\% MMT and CLNa.

Ahmad et al. ${ }^{24}$ observed that the addition of different amounts of $\mathrm{ZnO}$ increased the hydrophilic membrane characteristic. Besides, the high molecular weight of PES $(63,000 \mathrm{~g} / \mathrm{mol})$ provide a hydrophilicity characteristic to the membranes. Celik et al. ${ }^{25}$ showed that the presence of PES with a higher molecular weight caused the membrane to have a higher hydrophilicity and Fornes et al. ${ }^{26}$ observed that a better dispersion of the clay in a polymer matrix is given in polymers with high molecular weight, as, for example, in the studies realized in the polyamide 6 .

For the membranes with Brasgel clay, an average contact angle of $33^{\circ}$. The membranes containing the Cloisite $\mathrm{Na}$ clay had the same behavior as the ones with Brasgel clay. The membrane obtained an average contact angle of $32^{\circ}$. Both clays favored a greater hydrophilicity of the membrane, regardless of the origin and degree of purity of the membrane. This behavior in the decrease of the contact angle with the addition of clay was also observed by Carvalho et al. ${ }^{27}$.

Fig. 6 to 8 illustrate the cross-section SEM images of the PES membrane and the membranes with the different types of clay. The membranes presented an asymmetric structure with the presence of pores and macropores throughout the cross section. They have an extremely thin and apparently dense upper layer, where it is supported by the porous support, with the presence of pores, macropores and pores in the shape of "fingers". As is seen from the figures, there was a uniformity in the size and shape of the fingers, this may be attributed by the presence of DMF in the internal liquid during the preparation of the hollow fiber membranes. There was also the appearance of a dense layer at the center of the porous support, relatively thin, different from the literature ${ }^{18}$. The DMF acts to retard the precipitation, where the pores became smaller and more regular throughout the porous support of the membrane, modifying its morphology. 

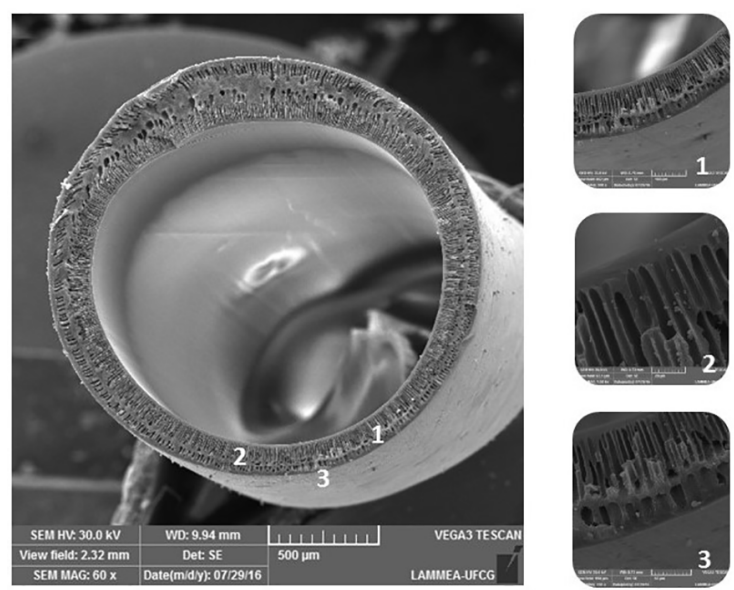

Figure 6. SEM photomicrographs of PES hollow fiber membrane.
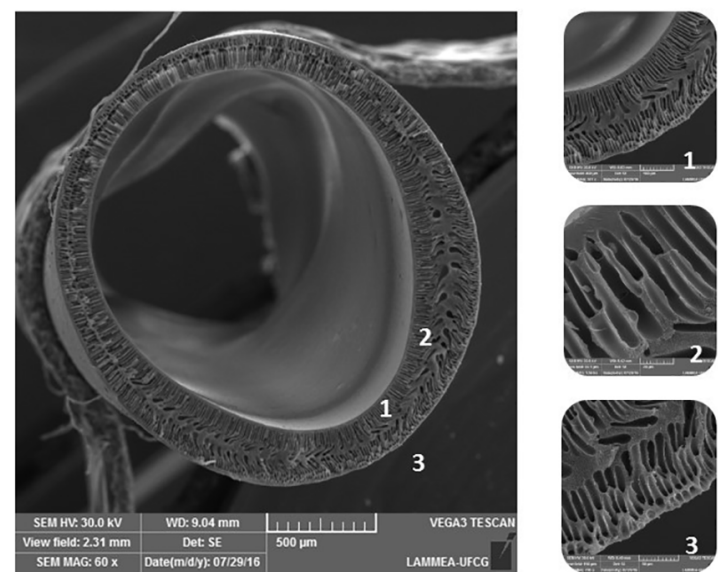

Figure 7. SEM photomicrographs of PES $+3 \%$ MMT hollow fiber membrane.
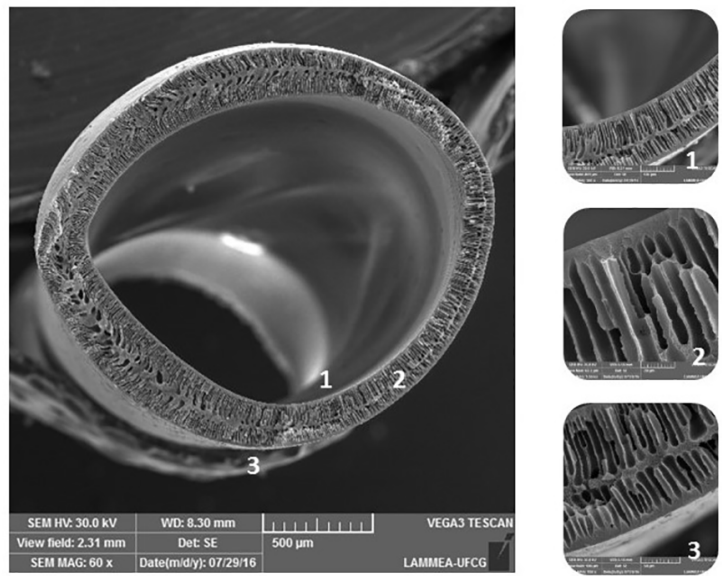

Figure 8. SEM photomicrographs of the hollow fiber membrane of PES $+3 \%$ CLNa.
Arthanareeswaran \& $\operatorname{Starov}^{28}$ studied the effect of the solvent on obtaining PES membranes by phase inversion. They evaluated the pure water flow, strength, mechanical stability and separation performance of these membranes. The researchers used N,N-dimethylformamide (DMF), N-methyl-2-pyrrolidone (NMP) and dimethyl sulfoxide (DMSO) as solvents and evaluated the performance of the membranes obtained. From SEM analysis, they verified that the PES membranes formed an asymmetric structure. The number of pores formed on the upper layer of PES membranes was a result of the combined effect of the thermodynamic properties of the system and the kinetics of membrane formation. The formation of the macroporous layer of these membranes was controlled by the diffusion rate of solvent and non-solvent (pure water). The order of the pure water flow of the membranes with different solvents was as follows: DMF $>\mathrm{NMP}>\mathrm{DMSO}$. Membrane strength and mechanical stability decreased with decreasing PES concentration, while increasing with solvent concentration.

Figure 6 shows the SEM images of the cross section of the PES membrane. The presence of macropores and "fingers" is visible, with a good uniformity, both in size and shape.

Fig. 7 and 8 show SEM images of the cross-sectional of membranes with $3 \%$ of MMT and CLNa clay, respectively. Comparing with the PES membrane (Fig. 5), the membranes containing clay showed a greater uniformity of the pores and macropores throughout the cross-section of the membrane. There was also a higher concentration of pores in the porous support, since the clay acted as a porogenic agent ${ }^{29}$. The membranes also presented well defined "fingers" than the PES membrane, confirming that the presence of clay acts directly on the membrane morphology of PES.

As seen by XRD, an exfoliated and/or partially exfoliated nanocomposite was obtained. The formation of this structure reduces the interaction between the polymeric chains, which results in a delay in the coagulation of the polymer in the presence of the clay. On the other hand, due to the hydrophilicity of the clay and the formation of bonds with the DMF, it increases the diffusion of non-solvent and decreases the DMF output, resulting in a delay in the coagulation of the polymer, causing a decrease in the pores and "fingers" formation ${ }^{19}$.

Fig. 9 shows the results of the flow measurement test with distilled water for the membranes produced with the test pressure of $1.0 \mathrm{bar}$.

In general, it can be seen that for all compositions the flow has tended to remain constant over time ${ }^{30}$, with values close to 5,20 and $22 \mathrm{~L} / \mathrm{m}^{2}$.h, for pure PES, PES $+3 \% \mathrm{MMT}$ and PES $+3 \%$ CLNa membranes, respectively. The PES membrane obtained a low flow when compared to the membranes with the presence of clay. For membranes containing clay, the ones that obtained a higher flow and better standard, throughout the time of the test, was the membrane containing 3\% CLNa. 


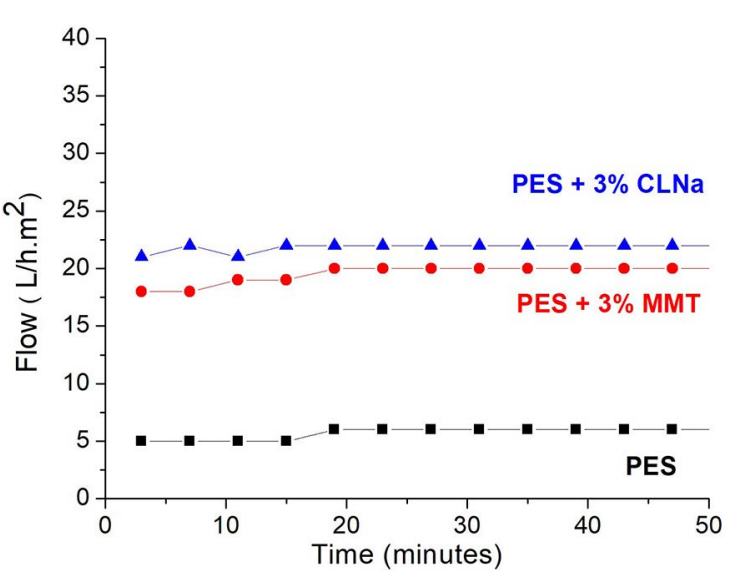

Figure 9. Flow measures with distilled water for pressure of $1.0 \mathrm{bar}$.

The presence of the solvent together with the amount of $3 \%$ of clay favored the membranes to have a higher permeability due to the more uniform morphology in both quantity and pore size as observed by SEM. The cross-section of the membrane acquired a greater uniformity as well as a smaller thickness of the dense layer in the center of the porous support, increasing the permeability of the membrane.

Fig. 10 shows image obtained by OM of the emulsion used for the experiment. It was possible to observe that there was a good homogeneity of the system, showing that the time and stir velocity were sufficient to produce a stable emulsion of oil in the distilled water. According to the Figure 9, the oil droplets have an average size of less than $10 \mu \mathrm{m}$ in the water/oil emulsion.

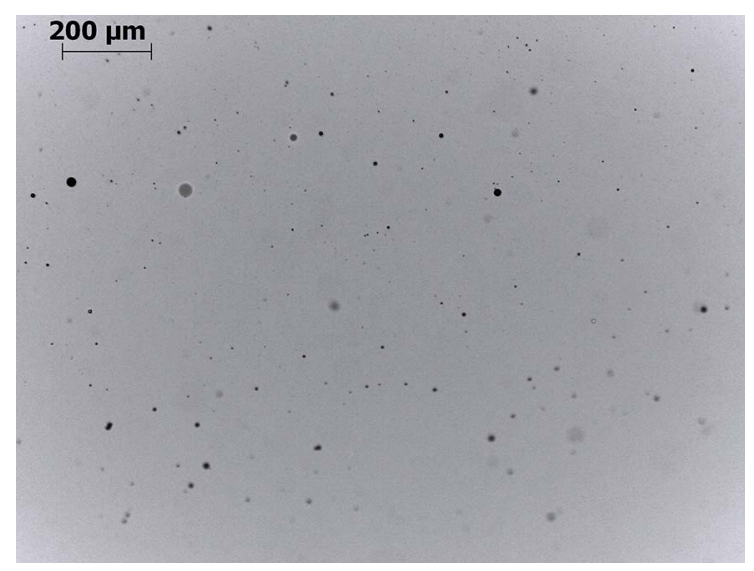

Figure 10. Images obtained by $\mathrm{OM}$ of the oil-water emulsion with a concentration of $200 \mathrm{ppm}$.

Fig. 11 shows the results of the water/oil flow measurement test through the porous membrane support under the pressure of $1.0 \mathrm{bar}$ for all membranes produced.

The membranes obtained a reduction (of $\sim 32 \%$ for $\mathrm{PES}+3 \% \mathrm{MMT}$ and $\sim 25 \%$ for PES $+\mathrm{CLNa}$ ) in the permeate flow with oil emulsion, when they are compared with the flow of distilled water (Fig. 9), showing that even with

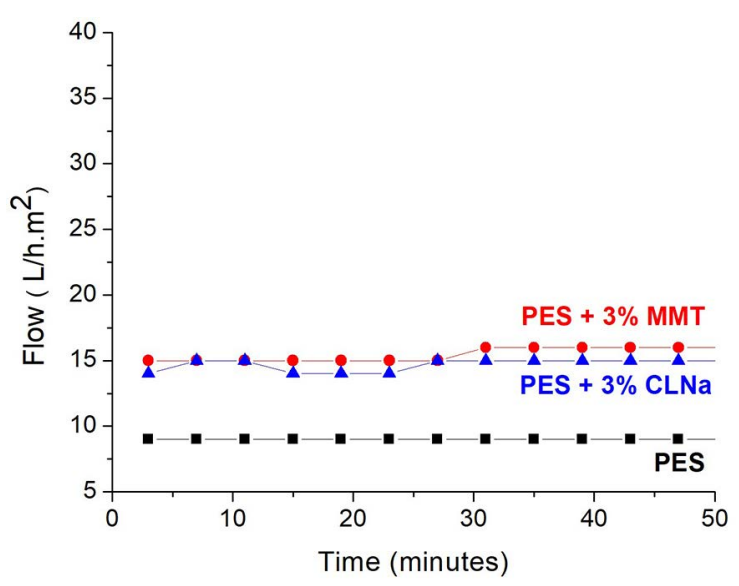

Figure 11. Flow measures with water/oil emulsion for 1.0 bar pressure.

a fluid with different characteristics, it was possible to have a pattern for all the membranes. The decrease in the permeate flow was attributed to the phenomenon of fouling, i.e., the formation of an oil crust on the surface of the membrane, which behaves as a barrier restricting the passage of the fluid ${ }^{31,32}$.

The membrane that obtained the greatest flux during the time was the one containing the montmorillonite clay. This can be attributed to a greater affinity of the water with this type of clay, causing the membrane to obtain a greater flow.

Table 4 presents the values of oil concentration in the permeate $(\mathrm{Cp})$ and the yield (rejection coefficient), using oily emulsion with concentrations $\left(\mathrm{C}_{0}\right)$ of $130,124,121 \mathrm{mg} . \mathrm{L}^{-1}$ for the Pure PES, PES + 3\% MMT and PES + 3\% CLNa membranes, respectively, at 1.0 bar of pressure.

In general, the yield of the membranes submitted to the water-oil emulsion flow, obtained significant oil reductions in the permeate collected ${ }^{33}$. Where the membrane with $3 \%$ CLNa obtained a lower final concentration of oil in the permeate of $26.6 \mathrm{mg} . \mathrm{L}^{-1}$.

The addition of PES $+3 \%$ CLNa clay in the membranes favored a greater reduction of the oil concentration in the permeate and for the membrane with $3 \%$ MMT, this did not occur. This last composition presents a low yield due to its larger size of the fingers and macropores, facilitating the passage of the oil to the permeate. It is possible to observe that it presented a greater flow, where can be supposed that also had a greater amount of oil in the permeate.

The results obtained show that the membranes containing clay can be applied for the purification of oily emulsions. As reported by Chakrabarty, Ghoshal \& Purkait ${ }^{34}$, MSPs represent a potential solution to the problem of oily effluent with microdroplet of oil. The emulsified oil can be retained by the size exclusion membrane by increasing its concentration in the feed stream and facilitating the coalescence of droplets of oil of micron and submicron dimensions into larger droplets so that they can be easily separated by gravity. 
Table 4. Values of $\mathrm{C}_{0}, \mathrm{C}_{\mathrm{p}}$ and yield calculated for Pure PES, PES $+3 \%$ MMT and PES $+3 \%$ CLNa membranes at a pressure of 1.0 bar.

\begin{tabular}{lccc}
\hline Membranes & $\mathrm{C}_{0}\left(\mathrm{mg} \cdot \mathrm{L}^{-1}\right)$ & $\mathrm{C}_{\mathrm{p}}\left(\mathrm{mg} \cdot \mathrm{L}^{-1}\right)$ & Yield (\%) \\
\hline Pure PES & 130 & 35.4 & 72.31 \\
PES + 3\% MMT & 124 & 40.2 & 66.75 \\
PES + 3\% CLNa & 121 & 26.6 & 78.58 \\
\hline
\end{tabular}

\section{Conclusions}

Polyethersulfone (PES) hollow fiber membranes, containing $3 \%$ of two types of clay (Brasgel PA - MMT and Cloisite NA - CLNa) was prepared with success. The results showed the formation of nanocomposites membranes with exfoliated and / or partially exfoliated structure for both types of clay. From a contact angle it became apparent that the clay increased the hydrophilicity and the water flow in the permeation tests with water and oily emulsion. The morphology of the PES hollow fiber nanocomposite membranes was changed with the presence of clays and provided an increase in the permeate flow of the membranes. The membrane with Brasgel PA clay in its structure presented the greatest flow $(\sim 16 \mathrm{~L} / \mathrm{h} . \mathrm{m} 2)$ and the membrane with Cloisite Na presented the greatest yield (78.28\%). Therefore, the clay acted by modifying both the morphology and the hydrophilicity of the polyethersulfone membrane, improving flow and yield.

\section{Acknowledgments}

The authors thank to BUN/PB, MCTI/CNPq, PNPD/ CAPES and CAPES, for the financial assistance.

\section{References}

1. Wang XL, Qian HJ, Chen LJ, Lu ZY, Li ZS. Dissipative particle dynamics simulation on the polymer membrane formation by immersion precipitation. Journal of Membrane Science. 2008;311(1-2):251-258.

2. Ferreira NL, Hochheim BP, Lourenço FMO, de Oliveira CF, Silva ATL, Silva TM. Comparação entre os tratamentos por esgotamento e membrana para a água ácida proveniente de refinaria de petróleo. The Journal of Engineering and Exact Sciences. 2018;4(1):143-152.

3. Zhang H, Li B, Sun D, Miao X, Gu Y. $\mathrm{SiO}_{2}-\mathrm{PDMS}-\mathrm{PVDF}$ hollow fiber membrane with high flux for vacuum membrane distillation. Desalination. 2018;429:33-43.

4. Xia QC, Liu ML, Cao XL, Wang Y, Xing W, Sun SP. Structure design and applications of dual-layer polymeric membranes. Journal of Membrane Science. 2018;562:85-111.

5. Sridhar S, Smitha B, Aminabhavi TM. Separation of Carbon Dioxide from Natural Gas Mixtures through Polymeric Membranes-A Review. Separation \& Purification Reviews. 2007;36(2):133-174.

6. Liu F, Hashim NA, Liu Y, Abed MRM, Li K. Progress in the production and modification of PVDF membranes. Journal of Membrane Science. 2011;375(1-2):1-27.
7. Zhu Z, Wang W, Qi D, Luo Y, Liu Y, Xu Y, et al. Calcinable Polymer Membrane with Revivability for Efficient Oily-Water Remediation. Advanced Materials. 2018;30(30):1801870.

8. Tao M, Xue L, Liu F, Jiang L. An Intelligent Superwetting PVDF Membrane Showing Switchable Transport Performance for Oil/ Water Separation. Advanced Materials. 2014;26(18):2943-2948.

9. Sengur R, de Lannoy CF, Turken T, Wiesner M, Koyuncu I. Fabrication and characterization of hydroxylated and carboxylated multiwalled carbon nanotube/polyethersulfone (PES) nanocomposite hollow fiber membranes. Desalination. 2015;359:123-140.

10. Zangeneh H, Zinatizadeh AA, Zinadini S, Feyzi M, Bahnemann DW. Preparation and characterization of a novel photocatalytic self-cleaning PES nanofiltration membrane by embedding a visible-driven photocatalyst boron doped- $\mathrm{TiO}_{2}-\mathrm{SiO}_{2} / \mathrm{CoFe}_{2} \mathrm{O}_{4}$ nanoparticles. Separation and Purification Technology. 2019;209:764-775.

11. Pereira BS, Moreti LOR, Silva MF, Bergamasco R, Piccioli AFB, Garcia EE, et al. Water Permeability Increase in Ultrafiltration Cellulose Acetate Membrane Containing Silver Nanoparticles. Materials Research. 2017;20(Suppl 2):887-891.

12. Liang CY, Uchytil P, Petrychkovych R, Lai YC, Friess K, Sipek M, et al. A comparison on gas separation between PES (polyethersulfone)/MMT (Na-montmorillonite) and PES/ $\mathrm{TiO}_{2}$ mixed matrix membranes. Separation and Purification Technology. 2012;92:57-63.

13. Muhamad MS, Salim MR, Lau WJ. Preparation and characterization of PES/SiO $\mathrm{S}_{2}$ composite ultrafiltration membrane for advanced water treatment. Korean Journal of Chemical Engineering. 2015;32(11):2319-2329.

14. Cirne I, Boaventura J, Guedes Y, Lucas E. Methods for determination of oil and grease contents in wastewater from the petroleum industry. Chemistry \& Chemical Technology. 2016;10(4):437-444.

15. Darós M, Barbosa RV, de Avila MC, Kloss J. Preparação e caracterização de compostos elastoméricos aditivados com cargas à base de bentonita. Revista Iberoamericana de Polímeros. 2015;16(4):197-205.

16. Santos PS. Ciência e Tecnologia de Argilas. Volume 1. $2^{\mathrm{a}}$ ed. São Paulo: Edgar Blucher; 1989.

17. Leite IF, Raposo CMO, Silva SML. Caracterização estrutural de argilas bentoníticas nacional e importada: antes e após o processo de organofilização para utilização como nanocargas. Cerâmica. 2008;54(331):303-308.

18. Ferreira RSB, Oliveira SSL, Leite AMD, Araújo EM, Lira HL. Modificação da Morfologia de Membrana de Polietersulfona a Partir da Presença de Argila Montmorilonita. Revista Eletrônica de Materiais e Processos. 2016;11(3):171-178. 
19. Ghaemi N, Madaeni SS, Alizadeh A, Rajabi H, Daraei P. Preparation, characterization and performance of polyethersulfone/ organically modified montmorillonite nanocomposite membranes in removal of pesticides. Journal of Membrane Science. 2011;382(1-2):135-147.

20. Wang Y, Zhang B, Ye J. Microstructures and toughening mechanisms of organoclay/polyethersulphone/epoxy hybrid nanocomposites. Materials Science and Engineering: A. 2011;528(27):7999-8005.

21. Zinadini S, Zinatizadeh AA, Rahimi M, Vatanpour V, Zangeneh $H$. Preparation of a novel antifouling mixed matrix PES membrane by embedding graphene oxide nanoplates. Journal of Membrane Science. 2014;453:292-301.

22. Rahimi M, Zinadini S, Zinatizadeh AA, Vatanpour V, Rajabi L, Rahimi Z. Hydrophilic goethite nanoparticle as a novel antifouling agent in fabrication of nanocomposite polyethersulfone membrane. Journal of Applied Polymer Science. 2016;133(26):43592.

23. Abdel-Karim A, Gad-Allah TA, El-Kalliny AS, Ahmed SIA, Souaya ER, Badawy MI, et al. Fabrication of modified polyethersulfone membranes for wastewater treatment by submerged membrane bioreactor. Separation and Purification Technology. 2017;175:36-46.

24. Ahmad AL, Abdulkrim AA, Shafie ZMHM, Ooi BS. Fouling evaluation of $\mathrm{PES} / \mathrm{ZnO}$ mixed matrix hollow fiber membrane. Desalination. 2017;403:53-63.

25. Celik E, Park H, Choi H, Choi H. Carbon nanotube blended polyethersulfone membranes for fouling control in water treatment. Water Research. 2011;45(1):274-282.

26. Fornes TD, Yoon PJ, Keskkula H, Paul DR. Nylon 6 nanocomposites: the effect of matrix molecular weight. Polymer. 2001;42(25):9929-9940.
27. de Cavalho TC, Medeiros VN, Leite AMD, de Araújo EM, Lira HL. Polyethersulfone/clay membranes and its water permeability. Matéria (Rio de Janeiro). 2017;22(2):e11825.

28. Arthanareeswaran G, Starov VM. Effect of solvents on performance of polyethersulfone ultrafiltration membranes: Investigation of metal ion separations. Desalination. 2011;267(1):57-63.

29. de Medeiros KM, Araújo EM, Lira HL, Lima DF, de Lima CAP. Membranas microporosas híbridas assimétricas: influência da argila na morfologia das membranas. Matéria (Rio de Janeiro). 2017;22(2):e11812.

30. Xiang T, Tang M, Liu Y, Li H, Li L, Cao W, et al. Preparation and characterization of modified polyethersulfone hollow fiber membranes by blending poly (styrene-alt-maleic anhydride). Desalination. 2012;295:26-34.

31. Zuo JH, Cheng P, Chen XF, Yan X, Guo YJ, Lang WZ. Ultrahigh flux of polydopamine-coated PVDF membranes quenched in air via thermally induced phase separation for oil/water emulsion separation. Separation and Purification Technology. 2018;192:348-359.

32. Zeng K, Zhou J, Cui Z, Zhou Y, Shi C, Wang X, et al. Insight into fouling behavior of poly (vinylidene fluoride)(PVDF) hollow fiber membranes caused by dextran with different pore size distributions. Chinese Journal of Chemical Engineering. 2018;26(2):268-277.

33. de Medeiros KM, Araújo EM, Lira HL, Lima DF, de Lima CAP. Hybrid Membranes of Polyamide Applied in Treatment of Waste Water. Materials Research. 2017;20(2):308-316.

34. Chakrabarty B, Ghoshal AK, Purkait MK. Ultrafiltration of stable oil-in-water emulsion by polysulfone membrane. Journal of Membrane Science. 2008;325(1):427-437. 